CASA, Vol.9 n.1, julho de 2011

c

Cadernos de Semiótica Aplicada

Vol. 9.n.1, julho de 2011

Publicação SEMESTRAL

ISSN: $1679-3404$

\title{
CINEMA HOLLYWOODIANO E CULTURA DE MASSA - ENTRE LEITORES, ESPECTADORES E EXPECTATIVAS
}

\section{HOLLYWOODIAN CINEMA AND MASS CULTURE - AMONG READERS, VIEWERS AND EXPECTATIONS}

\author{
Levi Henrique Merenciano ${ }^{1}$ \\ UNESP - Faculdade de Ciências e Letras de Araraquara \\ Centro Universitário Anhanguera - Uniderp
}

\begin{abstract}
RESUMO: Em trabalhos anteriores, estudei o leitor contemporâneo brasileiro e a sua relação com os livros mais vendidos com vistas a entender os motivos, no plano do discurso, que os levaram a se identificar com esses produtos da cultura de massa. Esse perfil de leitor brasileiro, constituído em textos verbais, levou-me a refletir sobre o reflexo da cultura de massas no âmbito do texto sincrético, materializado nas telas do cinema hollywoodiano. As expectativas do seu enunciatário devem ser explicadas por meio da organização discursiva dos filmes e de sua imagem neles projetada. Para tanto, as produções de cinema mobilizam temas e figuras, apropriam-se de símbolos, mitos, clichês, ressignificando-os de acordo com o tipo de espectador que pretendem agradar. O suporte teóricometodológico aplicado é o da Semiótica discursiva de base greimasiana. Os componentes do percurso gerativo de sentido e o exame das categorias da expressão serão recursos úteis para analisar duas produções hollywoodianas de cinema, X-men 3 e Crepúsculo, com o intuito de entender como cada um mobiliza a mesma figura da iconografia cristã: o Anjo da guarda. Também será apresentado como essa figura ocorre em outro discurso e que outros meios os filmes utilizam para disseminar ideologias específicas.
\end{abstract}

PALAVRAS-CHAVE: cultura de massa; cinema; Hollywood; espectador; expectativa; Semiótica.

ABSTRACT: In my previous papers I studied the contemporary Brazilian readers and their connection with the bestsellers, in order to understand the reasons, in discursive terms, which led them to appreciate these mass culture products. This reader profile, constituted in verbal texts, led me to reflect on the impact of mass culture in the syncretic texts, materialized on the screens of Hollywood motion pictures. The enunciatee's expectations must be explained through the discursive constitution of the movies and through the discursive image projected on it. Thereby, the film productions assemble themes and figures, appropriate the symbols, myths, clichés, giving them new meanings, according to the nature of viewer they want to please. The theoretical-methodological support applied is the discursive-based greimasian Semiotics. The components of the generative process of meaning and the exam of the categories of expression will be useful resources to investigate two Hollywood

\footnotetext{
${ }^{1}$ Doutorando do Programa de Pós-graduação em Linguística e Língua Portuguesa da UNESP - Araraquara. Professor tutor a distância do curso de Letras, no Centro Educacional Anhanguera-Uniderp.

Disponível em: http://seer.fclar.unesp.br/casa
} 
movies, "X-men 3" and "Twilight", in order to understand how they organize the same symbol from Christian iconography: the guardian angel. It will be presented, as well, how this symbol appears in other texts and which other resources movies use to disseminate specific ideologies.

KEYWORDS: mass culture; cinema; Hollywood; viewer; expectation; Semiotics.

\section{Introdução}

A pesquisa efetuada durante meus cursos de graduação e mestrado versou sobre o leitor contemporâneo brasileiro e a sua relação com os livros mais vendidos, com vistas a entender os motivos que o levaram a se identificar com esses produtos de massa. Incluo esses best sellers no contexto da cultura de massas, uma vez que são parte de um conjunto de manifestações discursivas englobadas pelas mídias contemporâneas, seja no plano verbal ou não verbal. A respeito das mídias em geral, contexto do qual os textos sincréticos fazem parte, Fiorin diz que os diferentes meios de comunicação - enquanto objetos de sentido - podem ser examinados à luz de teorias gerais da significação. $\mathrm{O}$ sentido gerado por um filme não é diferente daquele criado por um romance. É o plano da expressão que distingue um objeto do outro, e o seu plano de conteúdo é que comporta unidades de sentido semelhantes, sejam textos sincréticos ou não. Nesse caso, as semióticas modernas analisam as diferentes manifestações de sentido, não estando alheias a nenhuma forma de exprimi-lo (FIORIN, 2008, p. 78).

Estudar um perfil de leitor linguisticamente constituído no plano de conteúdo de livros mais consumidos levou-me a pensar sobre o reflexo desses produtos de massa no âmbito também do texto sincrético (a procura pela linguagem audiovisual materializada nas telas do cinema pop) e as estratégias discursivas que atendem às expectativas do espectador, sujeito enunciatário dos filmes de Hollywood. Ao ter acesso a essas produções (livros, filmes comerciais, entre outras manifestações textuais de massa), o público torna-se um consumidor de mercadoria cultural.

A indústria cultural, desde o século $\mathrm{XX}$, produz as suas tendências de acordo com as técnicas da imprensa, do rádio, da tevê, do cinema, propagando essa cultura para todas as esferas da vida. Ao circular por vários meios, forma um conjunto de objetos culturais (manifestações textuais) chamado cultura de massas, a qual é produzida segundo padrões de fabricação e destinada a uma massa social, a um aglomerado gigantesco de indivíduos (MORIN, 1987, p. 16). O cinema comercial (pop) é um exemplo disso. Ele encontra seu público por meio de uma síntese do padrão e do original exercida por meio de atrativos que unem elementos do arquétipo com o individual (ibid., p. 31). Estabelecendo um jogo entre o clichê e a novidade (o padrão e o original), o cinema pop toma cuidado para que o primeiro não fatigue e a segunda não seja difícil de compreender. Afirma Peñuela Cañizal (2004) que a diferença entre o cinema poético e o comercial reside em que o primeiro constrói-se em função de rupturas inerentes ao processo poético, enquanto o segundo prioriza as normas de continuidade exigidas pela lógica de concatenar enunciados narrativos (p. 19).

Ao cinema também está ligada uma espécie de cosmopolitismo, cuja intenção está em adaptar temas locais a fim de transformá-los em cosmopolitas, como o western, o jazz, os ritmos tropicais e latinos (samba, mambo, etc.). Esse tom universalizante favorece sincretismos culturais em cujo interior temas antropológicos são adaptados a um denominador comum de humanidade. Todo esse cosmopolitismo é irradiado a partir de um polo de desenvolvimento que domina esse processo: os Estados Unidos. "Foi lá que nasceu a cultura 
de massa. É lá que se encontra concentrado seu máximo de potência e energia mundializante" (MORIN, 1987, p. 44). Por sua vez, esses objetos culturais são destinados a uma espécie de anthropos universal, a um homem médio, geral. A ele corresponde um grau de humanidade comum a todos os outros homens (ibid., p. 44). Enfim, esse público alvo é materializado no sujeito que busca o jogo, o divertimento, o mito, a moral e, consequentemente, a identificação com aquilo que vê (projetando-se e sendo no filme representado):

A linguagem adaptada a esse anthropos é a audiovisual, linguagem de quatro instrumentos: imagem, som musical, palavra, escrita. Imagem tanto mais acessível na medida em que é envolvimento politônico [polifônico] de todas as linguagens. Linguagem, enfim, que se desenvolve tanto e mais sobre o tecido do imaginário e do jogo que sobre o tecido da vida prática (MORIN, 1987, p. 45).

Ao observar a procura por esses produtos de massa e a maneira como o espectador com eles se identifica, uma forma de entender as projeções do produtor (a coletividade de pessoas que produz o filme) e do espectador é focalizar a construção desses sujeitos discursivos (a imagem deles projetada nos filmes exibidos). Para que o espectador se identifique com as produções de cinema, elas devem mobilizar temas e figuras, apropriar-se de mitos, clichês, enfim, ressemantizá-los de acordo com o tipo de público que pretendem agradar. Destinando-se, portanto, a um público diverso, buscam obter o sucesso. Uma das imagens com a qual públicos de audiovisual e leitores se identificam é a do herói. A respeito da sua recorrência na cultura de massas (que encarna os mais diferentes personagens), Morin (1987, p. 92) nos explica que esse típico herói simpático (diferente do trágico) é aquele ligado ao expectador. O personagem que o representa, no caso do cinema, torna-se cada vez mais natural até não parecer mais um monstro sagrado executando um rito, mas um sósia exaltado do espectador. A este, o herói se liga por semelhanças e por uma simpatia profunda. Esse tipo de herói pode ser admirado ou lastimado, mas sempre é construído de forma a ser, no final da história, amado.

Outra questão ligada ao espectador é o happy end. No âmbito do cinema e da literatura, a ideia de felicidade torna-se o núcleo afetivo do imaginário cultural moderno. $\mathrm{O}$ happy end (final feliz) é um apego intensificado de identificação com o herói. Ao se aproximar da humanidade cotidiana, com problemas cada vez mais relacionados a mistérios, crises pessoais, desafios, etc., ele se torna um alter ego do espectador. O clima constante de simpatia nele focado instaura a felicidade como algo possível no plano do espectador também. O "final feliz" origina-se da adaptação de obras romanescas para o cinema (MORIN, 1987, p. 93-4). Ele é postulado pelo otimismo da felicidade e do esforço rentável, em que toda iniciativa nobre tem sua recompensa na Terra. Em suma, é uma aspiração originária do contexto do Welfare State e da busca pela felicidade privada, fatores ligados à realidade da década de 1930 em diante - a Grande Depressão e a necessidade de o Estado intervir na economia (ibid., p. 97).

Em seguida, será apresentado como os filmes contemporâneos se valem da imagem do herói, ligando-a ao imaginário cultural que o público tem a respeito dela.

\section{Literatura de massa e ideologia: textos de ação-intriga e de autoajuda.}

Em estudo sobre o que denomina literatura de mercado, Sodré (1988) descreve os procedimentos técnico-estéticos que explicam o processo de constituição dos best sellers e, por extensão, dos produtos da cultura de massas. O autor descreve obras de sucesso, como $O s$ 
mistérios de Paris, de Eugène Sue, por meio de elementos de interpelação herdados do gênero folhetinesco: o mito, a atualidade jornalística, o pedagogismo e a retórica consagrada da literatura anterior. Diz Sodré que a uma certa ampliação do folhetim estão ligadas obras como O Tubarão, de Peter Benchley - sucesso adaptado para o cinema, nos anos 70, por Steven Spielberg. Nela, os fatores de interpelação apresentados são usados para agradar a um mercado consumidor geral e acentuar ideologias (o isolacionismo norte-americano e o american way of life).

A cultura dos gibis também favorece ideologias ou dá ilegitimidade a outras. Como todo texto está inserido em um contexto, fazendo um pronunciamento sobre determinada realidade, a história do Super-homem não foge à regra. Arriscando uma breve análise, vemos que o personagem leva uma vida dupla. Na pele do Clark Kent, é um rapaz tímido, míope, cuja namorada ama o seu outro "eu", o Super-Homem. As suas características dispensam comentários: forte, belo, corajoso, poderoso e heroico. Discutindo a relação dos textos com a história, Fiorin (2001) explica que eles não precisam narrar fatos da história para com ela dialogar. A respeito de "super-homens", sabe-se que não existem. Mas o fazer desses personagens fictícios pode revelar anseios, ideias, concepções e temores de um povo de uma determinada época:

Nesse sentido, a narrativa do Super-homem mostra os anseios dos homens das camadas médias das sociedades industrializadas do século XX, massacrados por um trabalho monótono e por uma vida sem qualquer heró́smo. Esse homem, mediocrizado e inferiorizado, nutre a esperança de tornar-se um ser superpoderoso assim como Clark Kent, que se transforma em Super-homem (FIORIN, 2001, p. 28).

Como se percebe, um indivíduo com superpoderes poderia acabar com a fome, com a miséria e com todas as injustiças do mundo, sobretudo no contexto da Grande Depressão, época em que o ideário do Super-homem no gibi foi concebido. No entanto, ao significar anseios de uma época, em uma sociedade capitalista específica, vemos que o mal que combate é o atentado à propriedade privada: luta contra o mal combatendo ladrões (ibid., p. 27-28).

A respeito do ideário que pode ser criado em torno de obras de ficção e de personagens, heróis ou não, o universo dos livros mais vendidos atualmente fornece informações relevantes sobre a disseminação de ideias e sobre a identificação do leitor com seu conteúdo ficcional. Uma de minhas pesquisas sobre as expectativas do leitor brasileiro, "A leitura no Brasil de 1975 a 1990", mostrou como os livros mais vendidos relativos a esse período recente se valem de recursos discursivos para que o leitor contemporâneo se identifique com as histórias. Veremos que os conteúdos de ação-intriga, no plano de conteúdo dos textos mais vendidos, acompanharam os fatos conflituosos do período em que o leitor viveu.

Nessa pesquisa, realizei um estudo da organização discursiva dos livros mais vendidos no período 1975-1990, por meio das listas "ficção" da revista Veja. A partir dos rankings coletados, organizei um corpus que mostrasse uma visão global dos livros mais vendidos nas últimas décadas no Brasil. Observei que os mais vendidos refletiram as escolhas do leitor, pois alguns se relacionavam aos fatos históricos de então, ou dialogavam com tendências de comportamento social da época em que foram escritos. Nesse caso, sugeri um perfil de leitor para os anos 70 e outro, para a década seguinte. O exame discursivo dos mais vendidos nos anos 70 mostrou uma recorrência da oposição fundamental "opressão vs. liberdade. Na maioria dos discursos, um estado inicial de opressão (figurativizado por um 
tirano ou por um regime comunista, por terroristas ou pela ameaça de uma terceira guerra) devia ser combatido pelo fazer de sujeitos oprimidos (figurativizados como militantes de esquerda, guerrilheiros, comunidades campesinas oprimidas).

Em virtude dessa organização discursiva, as temáticas da Ditadura ${ }^{2}$ (em referência ao que ocorria no Brasil e na América hispânica) e da Guerra Fria ${ }^{3}$ (relacionada ao cenário internacional bipolarizado) confrontavam a temática do capitalismo, cujas histórias focavam a atuação de governos democráticos, considerados, portanto, os regimes libertadores.

Quanto aos mais vendidos de 1980 a 1990, observei um conjunto de manifestações discursivas de conteúdo mais heterogêneo (misto de ação-intriga com textos intimistas), cuja variância das estruturas fundamentais organizou-se de acordo com as oposições "ignorância vs. conhecimento", "humanidade vs. divindade" 5 e "essência vs. aparência". 6 Livros como As brumas de Avalon e A insustentável leveza do ser questionam o ser humano enquanto sujeito que deve transcender ou dar atenção à sua individualidade. À guisa de exemplo, o primeiro o faz de um ponto de vista da crença religiosa. Narra a vida de uma jovem que defende, na Idade Média, a seita pagã das bruxas (articulada com valores de divindade) frente à religião oficial cristã (articulada com valores de humanidade). $\mathrm{O}$ segundo faz um questionamento filosófico sobre a existência humana. Ao mostrar o paradoxo do peso (ligado à aparência) e da leveza (ligada à essência) inerentes à vida, explica a volubilidade e o peso das ações do homem. Fato comum nesses discursos mais subjetivos (ainda têm uma estrutura de ação-intriga) é o de já trazerem temas que, a partir dos anos 90, estariam no bojo da autoajuda e do esoterismo, como transcendentalismo e misticismo, por exemplo.

Baseando-me nesses resultados, durante o mestrado, realizei um exame dos textos de autoajuda mais vendidos, relacionados nas listas da revista Veja. Levando em consideração um tipo de leitor implícito, analisei os livros mais procurados nos anos 90 (categoria "autoajuda") e comparei a organização discursiva desses mais vendidos entre si. A partir do estudo de um novo corpus, sugeri uma tipologia discursiva para os textos estudados, de acordo com a observação das categorias semióticas do conteúdo - apresentado em Merenciano (2009). O critério tipológico, segundo Fiorin (1990), explica como se organizam discursivamente os textos. $\mathrm{O}$ gênero policial privilegia a fase da performance, valorizando o percurso da sanção, em que o criminoso é julgado. Por sua vez, um texto jornalístico sensacionalista expõe a fase da competência e a da performance (os meios para o acontecimento do fato e o desenrolar da ação). A autoajuda privilegia a fase narrativa da competência: doa um objeto-valor descritivo subjetivo (conhecimento) para um sujeito leitor já manipulado pelo querer ler.

Estudar como é projetado o etos discursivo é um recurso útil para analisar as projeções do autor no discurso e mostrar em que medida constrói a sua contrapartida (o enunciatário). Os estudos da enunciação buscam apreender sujeitos construídos pelo discurso, sendo imagens de leitor e autor, não os de carne e osso, mas discursivos (FIORIN, 2008, p. 82). Baseado em um conjunto de livros analisados, observei que o etos do enunciador da autoajuda é o de um sujeito que sabe da carência profissional e afetiva do leitor. Também constrói a imagem do seu enunciatário: um leitor que busca textos de leitura simples, com dicas de natureza prática para o seu dia a dia, como um manual técnico ou uma receita. Esses textos operam sob o regime da programação, instaurando um sujeito a que Greimas e Courtés

\footnotetext{
${ }^{2}$ Conversa na Catedral (VARGAS LLOSA, 1977); Fazenda Modelo (HOLLANDA, 1975).

${ }^{3}$ A alternativa do diabo (FORSYTH, 1979); O navegante (WEST, 1976).

${ }^{4}$ O nome da rosa (ECO, 1983); As areias do tempo (SHELDON, 1989).

${ }^{5}$ As brumas de Avalon (BRADLEY, 1985); O alquimista (COELHO, 1990).

${ }^{6}$ A insustentável leveza do ser e Risíveis amores (KUNDERA, 1985a; 1985b).
} 
(1979, p. 36) denominam autômato, pois deve seguir instruções específicas, à maneira de um texto injuntivo.

Enquanto manifestações textuais de massa, é possível aproximar o plano de conteúdo dos textos de autoajuda (textos verbais) com o dos textos sincréticos de Hollywood. A esse respeito, vejo diferenças quanto à manipulação. Acredito que a autoajuda atrai pelo recurso da tentação, por aquilo que de fato o enunciatário pode ganhar em autoconhecimento (saber), em que o leitor (manipulador) é levado a optar entre dois objetos-valor: positivo na tentação, negativo na intimidação (GREIMAS \& COURTÉS, 1979, p. 270).

Em contrapartida, os filmes comerciais atraem pela sedução. Não constroem o etos de um espectador carente, que vê na produção audiovisual de massas um meio para sanar um problema específico, pontual, como a autoajuda o faz. À maneira dos livros de açãointriga, os filmes comerciais provocam o prazer do espectador. Tal sedução é exercida por meio do espetáculo de ação, aventura, romance, suspense que oferecem. Nesse caso, o sujeito espectador, na posição de manipulado, exerce o fazer interpretativo e escolhe entre duas imagens de sua competência: positiva na sedução, negativa na provocação (ibid., p. 270). Ao escolher o valor eufórico (positivo) da manipulação, o público enunciatário aprova, assim, o entretenimento sedutor do filme.

Como todo texto ${ }^{7}$ é produzido num determinado contexto (estabelecendo com ele uma relação discursiva), a sétima arte manipula valores que da história fazem parte, seja a mais antiga ou a mais recente. Na mesma direção, os livros mais consumidos nos anos 70 remetiam aos contextos de ditaduras, militância e Guerra Fria de maneira objetiva (por meio de narrativas cinematográficas), à maneira de Sidney Sheldon, Frederick Forsyth, entre outros mais lidos. Mais subjetivamente, a literatura de autoajuda responde pelo consumo de textos direcionados às exigências do culto à individualidade, pois atende à determinada carência de conhecimento e ao apoio moral que o seu leitor assume não possuir na sociedade contemporânea.

Veremos, em seguida, que o diálogo do texto com o contexto é estabelecido, agora, por meio da figurativização do mito. Essa figura intertextual relaciona-se à performance do herói nos textos em questão.

\section{Cinema de massa: o anjo da guarda em Crepúsculo e $X$-men 3}

No âmbito do cinema, será apresentado como as produções de Hollywood refletem as escolhas do espectador contemporâneo (assim como o fizeram a literatura de massa já estudada: ficção e autoajuda). Por meio da fidúcia que estabelecem com o enunciatário, será observado de que meios discursivos esses objetos audiovisuais se valem para se relacionar ao contexto histórico, com outros textos (intertextualidade) e com as práticas discursivas relativas ao cenário cultural que os produz.

Para tanto, vejamos como duas famosas produções de Hollywood, X-men $3(2006)^{8} \mathrm{e}$ Crepúsculo (2008) ${ }^{9}$, dentre as mais vistas nos respectivos anos, mobilizam a imagem do mito do anjo da guarda, de maneira a se identificar com o espectador.

\footnotetext{
${ }^{7}$ Chamamos os discursos audiovisuais de texto, porque, enquanto unidade de sentido, um texto pode ser organizado por diferentes linguagens (que não somente a oral e escrita), a exemplos dos textos pictóricos ou sincréticos (imagem e som). Essas formas de representação podem ser estudadas dentro de sua estrutura e de sua historicidade, uma vez que são enunciados em um determinado contexto e por um sujeito discursivos.

${ }^{8} \mathrm{http}: / /$ boxofficemojo.com/yearly/chart/?yr=2006\&p=.htm

${ }^{9} \mathrm{http}: / /$ boxofficemojo.com/yearly/chart/?yr=2008\&p=.htm
} 
À primeira vista, a adaptação para o cinema do romance de vilões e mocinhos de Stephenie Meyer, Crepúsculo (2008), traz como tema um clichê: a aceitação da mudança de lar e as suas consequências na vida de uma adolescente. Bella Swan vive com a mãe divorciada em Fênix, uma cidade de clima quente e agradável. Como sua mãe necessita de mais privacidade com o seu novo marido, Bella muda-se indefinidamente para a cidade do seu pai solteirão, Forks, um local próximo às montanhas, sempre chuvoso, frio, úmido. Ao estabelecer-se lá, a garota procura fazer novas amizades e adaptar-se à nova escola. Em uma das aulas, conhece seu futuro namorado, Edward Cullen, cuja refinada família guarda mistérios (são reservados e de pele pálida). A discrição dos Cullens deve-se ao fato de serem vampiros.

A segunda vez que Bella avista Edward na escola, ele está sentado próximo à janela, durante a aula de biologia. Ao se olharem, ele apresenta uma estranha repulsão, explicada pela atração que não consegue evitar sentir por Bella. Bem atrás de Edward, há uma coruja branca de asas abertas (parecendo estar sobre seu ombro), cujo efeito de sentido, no enquadramento (Figura 1), o transforma, via metáfora, tanto em um ser alado (um anjo), como no possuidor do bicho de hábitos noturnos.

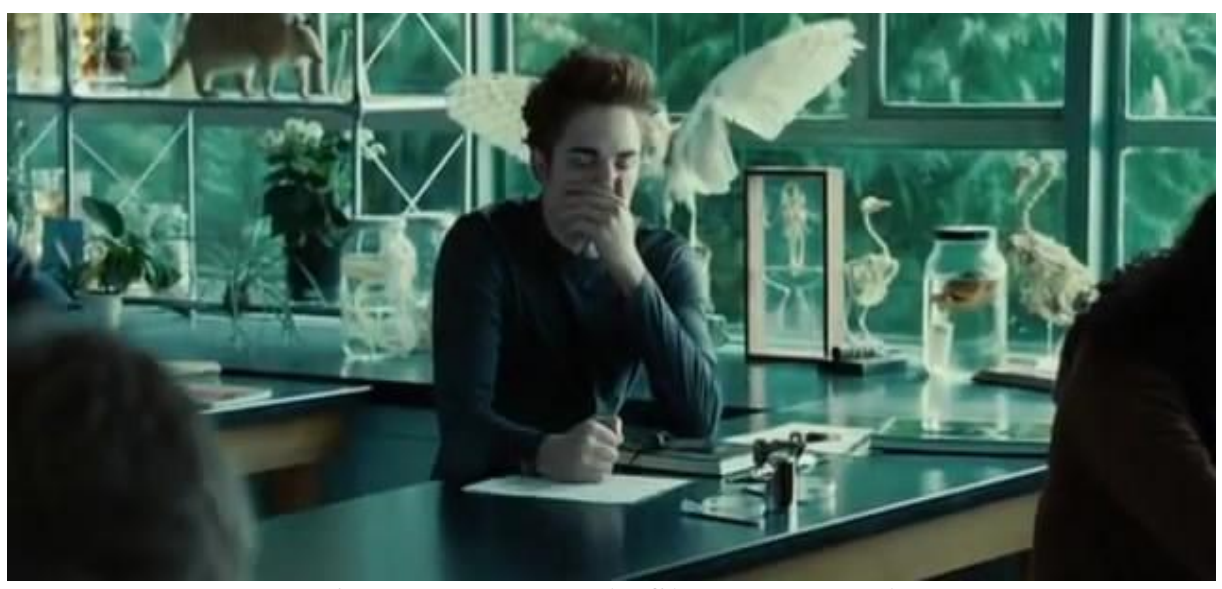

Figura 1: Imagem do filme Crepúsculo (2008).

No que diz respeito às características da coruja branca, percebe-se que, ao mesmo tempo que Edward é um ser noturno (como a coruja), também será, pouco tempo depois, o anjo da guarda de Bella (indicado pelas asas angelicais metafóricas), pois a salva, em seguida, de um acidente de carro e de outros incidentes futuros. Outro enquadramento, em close, mostra uma das asas do animal como se pertencesse ao rapaz (Figura 2), projetada à direita, em diagonal, para cima. A metáfora construída a partir de uma coruja relaciona, por um lado, o hábito noturno do animal ao tema do vampirismo. 


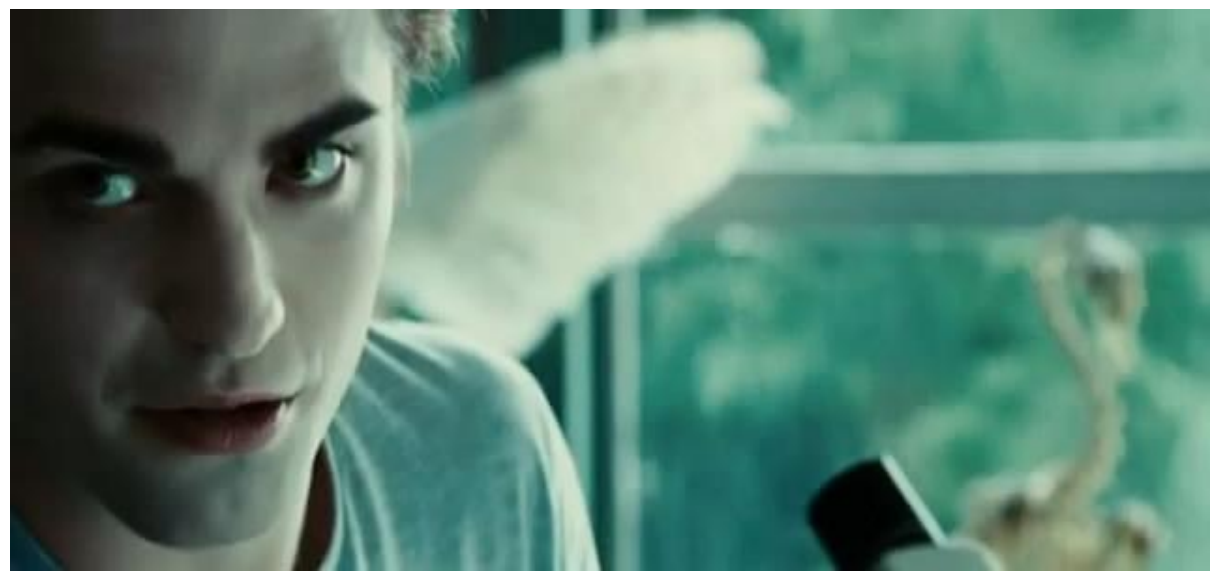

Figura 2: Imagem do filme Crepúsculo (2008).

Por outro lado, a combinação dos semas "branco", "alado" e "noturno" relaciona-se a elementos discursivos que remetem às atitudes e características de Edward: é pálido como o branco que traz a paz (mesmo que "branco = paz" pareça clichê) ${ }^{10}$ protetor como o anjo da guarda; noturno como a coruja; e voador, metonimicamente, como a águia norte-americana (contexto cultural do qual o filme faz parte). A unidade de sentido dessa figura (paradoxal) reside no fato de o filme tratar de vampiros bonzinhos. O fato de ser menos corado que os vampiros inimigos remete à sua dieta à base de animais. Por esse motivo (não se alimentar de sangue humano), Edward e sua família são, no filme, "vampiros vegetarianos"; por isso, diferentes (a sua pele revela-se dourada ao sol, não dormem em caixões e praticam esporte, o beisebol).

Como esse discurso tem uma abordagem euforizante (vampiros protetores, vegetarianos, pacíficos, bonitos, esportivos e dourados), o público identifica-se com os personagens e com a sua história, a qual aborda o tema soturno do vampirismo de um ponto de vista se não muito diferente, sugestivo. Essa relação intertextual com o anjo da guarda (símbolo de proteção) causa empatia com o espectador, pois se identifica com a figura do herói. Afinal de contas, são vampiros heróis, modernos, sedutores que, à maneira do herói simpático, identificam-se com o público e buscam o happy end.

O enredo do filme X-men 3 - o confronto final (2006) apresenta um tema diferente da história dos vampiros: a intolerância social. Na atualidade, há uma raça de humanos que, devido à mutação genética, adquire poderes especiais. Como são oprimidos pela sociedade, têm de lutar para conseguir espaço social. O rapaz alado (Figura 3), chamado Arcanjo escondia o poder de X-men do seu pai cientista, inventor da vacina contra a mutação (à esquerda). No entanto Arcanjo devia enfrentar a autoridade do pai (que representa o actante coletivo "opinião pública contra os X-men") a fim de poder ser livre e se colocar socialmente como um mutante não oprimido.

${ }^{10}$ É interessante observar que o cromatismo branco do campo semântico do vampirismo é tido como disfórico (pálido, sem vida), pois está associado aos valores do mal. O paradoxo relativo à cor branca, em Crepúsculo, ocorre por não estar associado a objetos valorizados negativamente, mas a valores de proteção vindos de uma espécie de "vampiro-anjo-herói". 


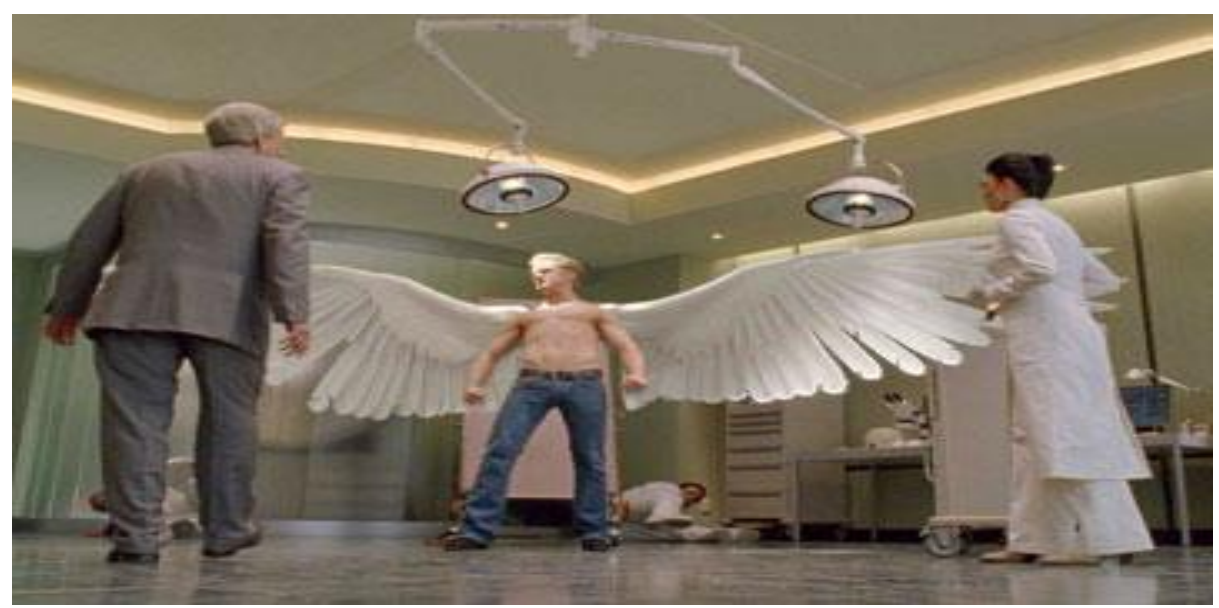

Figura 3: Imagem do filme $X$-men 3 - o confronto final (2006).

A sua liberdade é então afirmada quando sai voando através da janela do laboratório em que está, enfrentando os valores sociais de opressão e, assim, toda a opinião pública que apoiava a vacina antimutação. No que diz respeito à iconografia cristã, temos representada novamente a figura do anjo da guarda investida, portanto, dos semas "liberdade" e "proteção", assim como o sentido implícito na representação das asas posicionadas atrás do vampiro Edward (Figura 2). No entanto o personagem de $X$-men está explicitamente marcado com as asas, pois são reveladas como parte do seu ser.

Os filmes analisados mostram, assim, recursos figurativos usados para ressignificar um mito da iconografia cristã, o anjo da guarda (supondo ser compartilhado pela cultura ocidental que ao filme assiste). Ao ser referenciado nas produções em questão, esse mito representa conteúdos de proteção, liberdade e paz, provocando uma relação semântica eufórica de identificação com o público a partir de procedimentos recorrentes no cinema: metáfora e intertextualidade.

\section{Ideologias propagadas nas telas}

Uma outra forma de pensar como se organiza a unidade de sentido das produções de Hollywood é relacioná-las ao contexto histórico recente. Exemplo disso pode ser visto a partir de 2001, contexto a partir do qual foi produzida uma quantidade significativa de filmes que remetem aos atentados de "11 de setembro". Esse fato está presente em mensagens recorrentes tanto nos filmes de super-heróis, quanto nos filmes de guerra moderna (Guerra ao terror, de 2009, Zona Verde, de 2010, etc.), cujos conteúdos dialogam com a realidade histórica instaurada a partir do conhecido ataque às torres gêmeas.

No caso dos filmes de guerra citados, o primeiro funciona como uma espécie de encorajamento à participação da guerra no Iraque, pois apresenta um bravo soldado com vocação para desarmar bombas e para atuar na infantaria. $\mathrm{O}$ segundo procura justificar erros da inteligência norte-americana, quando não foi capaz de provar que havia "armas de destruição" no Iraque, figurativizado como um território inóspito, onde vivem homens primitivos. A esse respeito, em muitos filmes, ficam retratadas ficcionalmente as implicações surgidas no cenário mundial a partir da intensificação bélico-política da Casa Branca no Oriente Médio e em outros países cujo regime político é considerado por Washington como não democrático e autoritário. 
A ficcionalidade de Hollywood é como uma "segunda pele" da cultura norteamericana, no que essa cultura tem de pragmática, funcional, democrática, narcisista, compulsiva e consumista. É evidente que há um componente imperialista na ideologia do cinema de Hollywood, como há na tessitura histórica e cultural norte-americana. No seu debate sociocultural, é estratégico que esse componente seja assinalado e também que sejam atualizadas as modalidades críticas e histórico-interpretativas (PAIVA, 2010). A partir da relação desse ponto de vista com os fatores culturais e contextuais, esses filmes transmitem no seu plano semionarrativo - mensagens que procuram compensar falhas históricas ou enaltecer a cultura ianque que os produz, seja pelo incentivo à participação em guerras, seja pela aversão a tudo o que faça parte da cultura do Oriente Médio e, por extensão, a outras culturas do terceiro mundo (a africana, a latina, a do Leste europeu) ou as que não compartilham do ideário american way of life. Em resumo, os temas que parecem não interessar à cultura produtora do filme (a norte-americana) são figurativizados já em produções dos anos 80 como formas de cultura pobre, ruim, ilegítima, rústica, artificial, sem tradição, etc.

Em Rocky 4 (1985), estrelado por Sylvester Stallone, cujo tema central é a superação por meio do esporte, toda espécie de maniqueísmo é empregada para afirmar a cultura capitalista em detrimento da socialista no contexto da Guerra Fria. No início do filme, o amigo de Rocky, Apolo Creed, desafia um famoso boxeador russo, Drago, para uma luta nos Estados Unidos. Na ocasião do combate, todo o ideário do american way of life é apresentado ao espectador, antes da luta, em toda a sua magnitude de cores, músicas, felicidade, explosão de fogos e euforia, à maneira de um show da Broadway.

Mesmo com a recepção calorosa (e não menos provocativa), durante a luta, o russo não respeita o oponente e bate em Apolo até o matar. A partir disso, Rocky buscará vingar, no ringue, seu amigo morto. A construção de espaço e tempo relativa à União Soviética causa o efeito de que o ideário comunista é artificial, fechado, escuro, denso, sério. No extremo oposto está Rock Balboa. Observa-se que é visivelmente mais fraco e mais baixo que o seu oponente russo. Apelidado de "garanhão italiano", Rocky treina ao ar livre (Drago fica somente no laboratório), é um cara simpático (não se vê expressão no rosto de Drago), tem vida social (Drago se parece mais com um robô), não toma anabolizantes (o russo sempre os injeta) e topa desafiar o russo em terreno inimigo. No final, Rocky vence, sendo aclamado pelos russos em território soviético, representando a imagem do herói simpático e um belo final feliz, nos braços da esposa.

Até mesmo em seriados cômicos (na série transmitida pelo canal SBT, $E u, a$ patroa e as crianças em 2001), culturas estrangeiras do terceiro mundo são estereotipadas, sobretudo latinos e árabes. Em um dos episódios, quando o personagem central Michael Kyle procura aulas de dança, é seduzido por uma professora brasileira. A esposa, não gostando da forma como o Michael agia na presença da moça, chama-a de brasileira fácil. É caracterizada, pois, como uma pessoa oferecida, que "samba" uma coisa parecida com salsa e se oferece para Michael na frente da sua esposa, sem pudor.

A hostilidade a culturas estrangeiras, por exemplo, já vem sendo apresentada em alguns filmes de heróis. O povo árabe é geralmente figurativizado, seja pela característica corporal, seja pelas suas ações, como um povo mau, feio, pouco receptivo, sujo, sem cultura e intolerante. Logo no início de Homem-Aranha 2 (2004), o herói Peter Parker (HomemAranha) é demitido pelo seu patrão (com rosto e sotaque definitivamente árabes). Peter trabalha como entregador de pizzas em Nova Iorque. Uma das normas da empresa é dar o direito de o consumidor não pagar o pedido da comida caso seja entregue atrasado. O patrão exige que Peter faça uma entrega grande de pizza em poucos minutos. Como Peter necessitou 
resolver alguns imprevistos pelo caminho (salvar pessoas das mãos de criminosos), não cumpre o tempo mínimo de entrega do produto. Por isso, o cliente não lhe paga. Ao voltar para o trabalho, Peter implora para não ser despedido; seu patrão árabe é irredutível e o demite, sem levar em conta (pois não sabia) o esforço do jovem herói trabalhador. Fica explícito que o empregador, mesmo sendo aceito em terra estrangeira, comporta-se de modo intolerante, não querendo sequer ouvir as explicações do herói.

\section{4. $O$ cinema de Hollywood e as categorias da expressão}

A respeito das categorias da expressão, existem métodos semióticos de análise para o estudo do semissimbolismo, que resulta da articulação das categorias do conteúdo com as da expressão. Floch (1985) formaliza essas categorias plásticas em três tipos: a eidética (forma dos traços), a cromática (disposição de cores) e a topológica (planos da imagem). Em Un nid comfortable, Floch aplica essas categorias da expressão ao estudo da charge em questão, relacionando-as ao seu plano de conteúdo. "Um ninho confortável" é uma breve narrativa pictórica, cujos seis quadrinhos revelam como um pássaro constrói para si um ninho à custa de um bambolê e de um chapéu tirados de um garotinho.

$\mathrm{Na}$ charge, as categorias axiológicas de conteúdo "natureza vs. cultura" estão homologadas às da expressão "alto $v s$. baixo" (topológicas) e "verticalidade $v s$. horizontalidade" (eidéticas). Assim como existem categorias do conteúdo (de espaço, tempo e pessoa), também podem ser aplicadas ao estudo dos textos sincréticos categorias próprias para análise da expressão.

Não somente as categorias do plano de conteúdo compõem uma unidade de sentido que corresponde às expectativas do público. Segundo Pietroforte (2007, p. 67), a manipulação do espectador também diz respeito às categorias da expressão. Os objetos visuais, examinados pela Semiótica plástica, determinam o ponto de vista do espectador. Esse modo de olhar presente na fotografia, na pintura, etc. gera efeitos de sentido a partir da combinação das categorias da expressão. Um dos recursos da manipulação da leitura dá-se a partir do enquadramento, por meio do qual tanto os quadrinhos quanto o cinema contribuem com processos semióticos semelhantes.

Não é de se admirar que um dos recursos de filmes de sucesso como E.T - $O$ extraterrestre (1986) seja os efeitos subjetivos provocados pelo enquadramento da câmera. A preferência pelas tomadas em contra-plongée (de baixo para cima) não só mostram o ponto de vista do espectador infantil (daí a sua identificação com o filme), como fazem o adulto sentirse como uma criança que contempla o mundo de baixo. Nesse caso, o enunciado coloca o enunciatário espectador em um ponto de vista subjetivo (diferente de uma imagem panorâmica, por exemplo), parecendo olhar por sobre o ombro do simpático e pequenino E.T. (Figuras 4, 5, 6). 

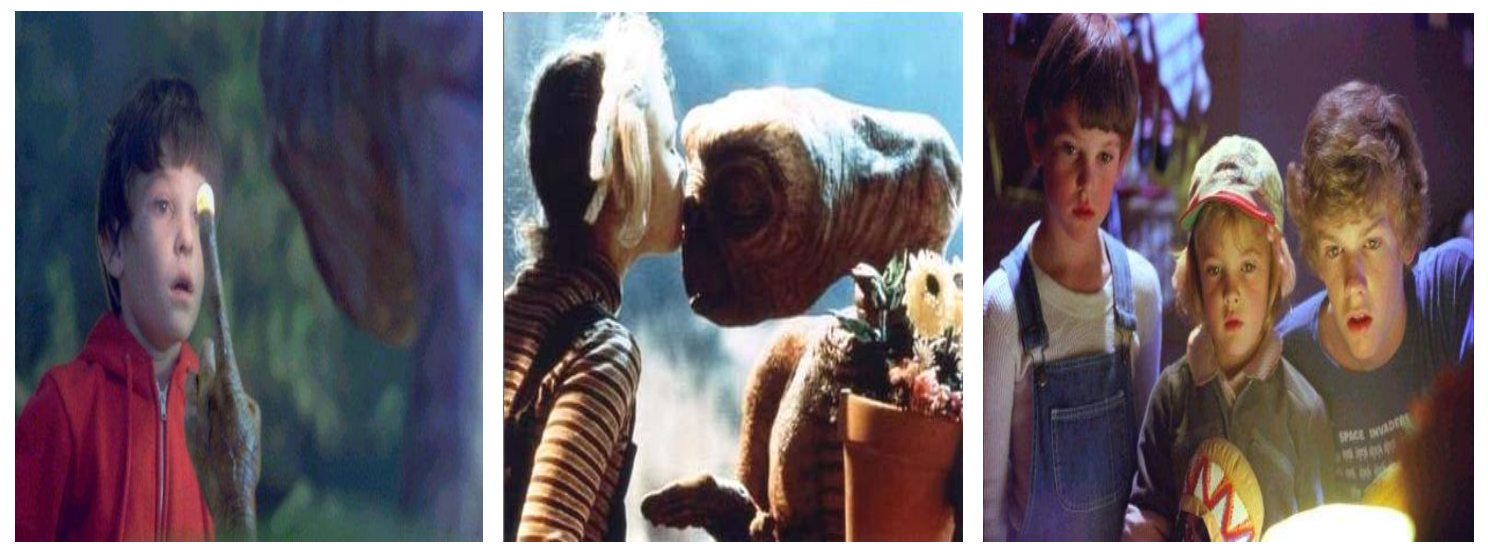

Figuras 4, 5 e 6: Imagens do filme ET - o extraterrestre (1986).

Seguindo a mesma linha de filmes de ação futurísticos como Blade Runner, está $E u$, robô (2004). Nada mais comum do que, em um filme cheio de máquinas, pessoas frias e muita tecnologia, haver um herói "bacana", "descolado", impulsivo e saudosista, encarnado pelo simpático Will Smith.

No ano de 2035, o detetive Spooner (Will Smith) é encarregado de procurar um robô assassino que infringiu o código de não matar humanos. É interessante como o protagonista Spooner afirma o seu modo de ser, uma vez que não gosta de robôs, enfim não lida bem com o mundo tecnológico que o rodeia. Em virtude disso, prefere ter móveis antigos em casa. A forma como se veste é "retrô", usa um tênis "descolado" (All Star), e suas roupas são predominantemente em tons de cinza a preto (heterocromatismo). O seu comportamento instintivo e seu andar cambaleante e despojado (obliquidade) contrastam com o comportamento da doutora Susan. O andar dela é reto (retilineidade), assim como a sua postura ética e corporal. O seu modo de agir é racional, calculado. Susan não infringe normas, e em suas vestimentas predomina o monocromático.

Um dos pôsteres de $E u$, robô (2004) marca as categorias eidética e cromática por meio de duas figuras (homem e robô) nas extremidades da foto (excetuando a parte central, com uma faixa alaranjada de propaganda):

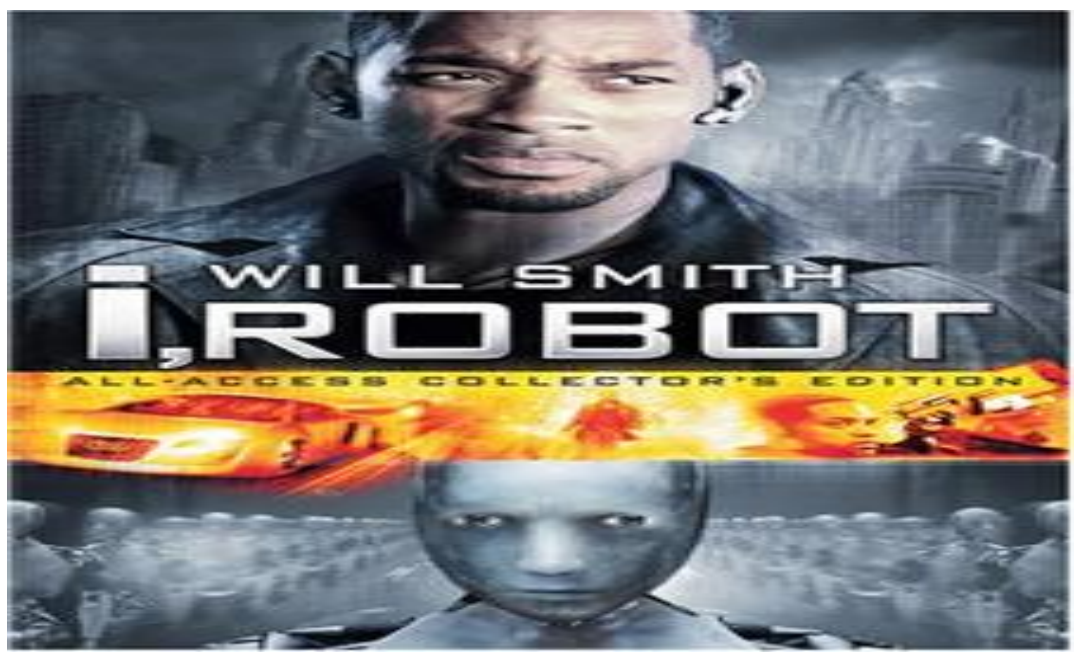

Figura 7: Um dos pôsteres do filme $E u$, robô (2004).

Fonte: http://www.adorocinema.com/filmes/eu-robo 
$\mathrm{Na}$ extremidade superior, Spooner está inclinado para a direita e olha enviesado; os prédios, ao fundo, também têm traços oblíquos; a sua vestimenta tem tons heterocromáticos, assim como a luz e a sombra projetadas no seu rosto. Essa extremidade da foto é regida pelo oblíquo, assim como o "torto" da imperfeição faz parte da sua vida. Na extremidade inferior, está a imagem de um robô centrado, que olha para frente, fitando o espectador; ao fundo, duas fileiras de robôs idênticos formam um corredor preciso, exato; o jogo de cores é regular, monotonal. Essas categorias da expressão remetem a conteúdos de exatidão e clareza tecnológicos. O que causa empatia é o fato de o agente herói defender a causa humana e agir como humano em um filme futurístico, de máquinas.

Enfim, o agente Spooner remete à humanidade sem tecnologia, dependente dos instintos (homem que age sobre as coisas). Já, Susan, como cientista, remete à mediação da tecnologia homem-mundo. Ela é um ser extremamente racional, enquadrado, futurista (ele é impulsivo, sinuoso, saudosista). As categorias da expressão relativas a Spooner (eidética e cromática) destacam, no plano de conteúdo, a luta do homem contra a máquina. Há, por isso, uma relação semissimbólica das categorias do conteúdo (tecnologia, perfeição vs. humanidade, imperfeição) com as da expressão (retilineidade, monocromatismo vs. obliquidade, heterocromatismo):

\begin{tabular}{|l|l|l|}
\hline Plano de conteúdo & Tecnologia $v s$. humanidade & Perfeição $v s$. imperfeição \\
\hline Plano de expressão & Retilineidade $v s$. obliquidade & Monocromatismo $v s$. heterocromatismo \\
\hline
\end{tabular}

Aliás, outras capas revelam a obliquidade relativa a Spooner - em inglês, aliás, o substantivo spoon significa colher - utensílio, por sinal, curvado, torto:
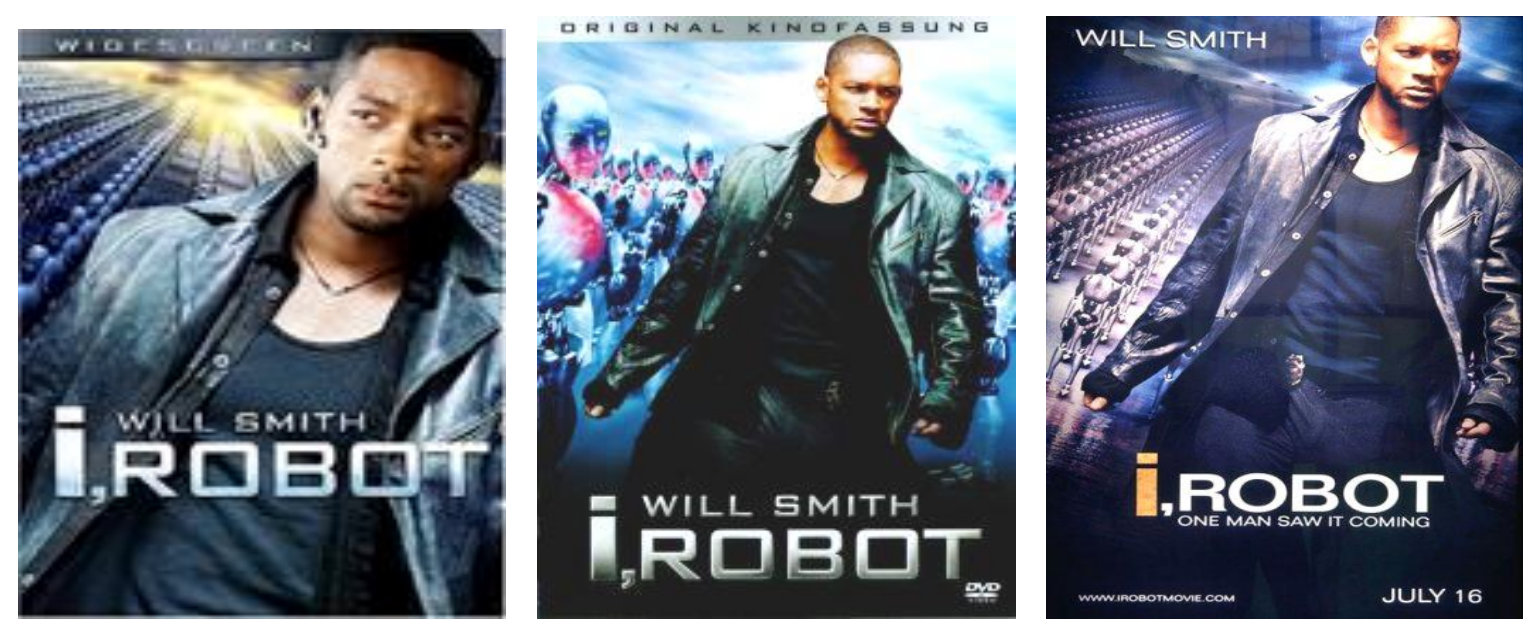

Figuras 8, 9 e 10: Pôsteres do filme Eu, Robô (2000).

Fonte: http://www.adorocinema.com/filmes/eu-robo.

Observamos, portanto, que a relação semissimbólica compreende os dois planos da linguagem. Enquanto uma categoria do conteúdo tem uma coerência semântica, uma categoria do plano de expressão tem uma coerência plástica (PIETROFORTE, 2004, p. 97). A forma como as categorias da expressão estão dispostas podem também direcionar o ponto de vista do espectador, seja com relação às características do herói, seja enquanto manipulação do ponto de vista do sujeito enunciatário, como em E.T. 
CASA, Vol.9 n.1, julho de 2011

\section{Considerações finais}

Tendo em vista a análise de objetos textuais diversos, sejam verbais ou não verbais (especificamente sincréticos), pôde ser observado como diferentes discursos (em livros e filmes) manipulam símbolos, mitos, clichês, com vistas a estabelecer uma unidade de sentido a partir da construção de valores eufóricos (o anjo, por exemplo), destinados a persuadir um público geral ou, nas palavras de Morin (1987), um anthropos universal, um homem médio. No âmbito desses objetos culturais heterogeneamente constituídos, é possível estabelecer uma relação de sentidos que dialogam com elementos contextuais, intertextuais, por meio de recursos linguísticos e expressivos, a fim de construir coerentemente um objeto de significação.

Em suma, vimos que a figura do anjo da guarda (analisada em dois textos) mobiliza mensagens direcionadas a um público geral, pois a ela não está relacionado um conteúdo de crítica explícita, mas uma performance de uma espécie de herói simpático, feito à semelhança da imagem que o público tem de alguém bravo, corajoso, humilde e leal (seu alter ego projetado). Essa é a imagem que o homem médio tem de alguém corajoso e procura, portanto, ter de si. Ao identificar-se com esse outro "eu" fabricado, espera, assim, que essa figura satisfaça suas expectativas, guiando seu querer, seus anseios para um belo happy end.

Por outro lado, os filmes de guerra citados, o clássico Rocky 4, Homem-Aranha 2 e a série de tevê do canal SBT mencionados valem-se de recursos que, ao favorecerem e, ao mesmo tempo, euforizarem valores ianques, fazem a compressão dos objetos culturais desse povo estar vinculada à imagem de um público específico que assimile essas mensagens e as entenda como parte do seu universo cultural. Nesse caso, o público-alvo é o norte-americano sobretudo, além de outras culturas que pelo ideário estadunidense são influenciadas, seja por meio do consumo dos seus produtos culturais, seja pela simples assimilação automática do que se assiste.

Mesmo assim, quando são expostos traços negativos de outras culturas por meio de estereótipos (o soviético frio, o latino "caliente", o árabe rústico e quase "neolítico"), valoriza-se o que não faz parte delas (pois com essas culturas faz oposição), como: o bravo soldado norte-americano; o boxeador campeão e garanhão italiano Rocky; o jovem herói aracnídeo Peter Parker; o impulsivo e humano agente Spooner; e o bem-sucedido empresário e esposo fiel Michael Kyle.

Todas essas representações evocadas pelas imagens, projetadas por meio de recursos de conteúdo e de expressão, constroem um todo de sentido, uma vez que buscam a sua coerência a partir do diálogo com os temas contemporâneos ou com os de outrora, que, situados em histórias aparentemente sem pretensão (ficcionais, de entretenimento), metamorfoseiam sentidos, recriam ideias, evocam mitos, refazem clichês. Sendo apresentados a um microuniverso tão denso de expectativas e espectadores, oferecem a sua contribuição enquanto manifestações culturais destinadas às grandes massas. Por meio do cinema (e por entre outros suportes e contextos), esses objetos culturais navegam e se embrenham pelos diversos segmentos sociais e contextos culturais.

\section{Referências bibliográficas}

BRADLEY, M. Z. As brumas de Avalon: a senhora da magia. Tradução de Waltensir Dutra e Marcos Aurélio P. Cesarino. Rio de Janeiro: Imago, 1985.

COELHO, P. O alquimista. 26 ed. Rio de Janeiro: Rocco, 1990. 
CREPÚSCULO. Direção Catherine Hardwicke. Estados Unidos: Summit Entertainment / Paris Filmes, 2008. 1 DVD (122 min.), sonor., color.

ECO, U. O nome da rosa. 6 ed. Tradução de Aurora Fornoni Bernardini e Homero Freitas de Andrade. Rio de Janeiro: Nova Fronteira, 1983.

EU, a patroa e as crianças. Estados Unidos: Touchstone Television, 2001 a 2005. (20 min.), sonor., color. (Série de televisão).

EU, robô. Direção: Alex Proyas. Estados Unidos: 20th Century Fox Film Corporation, 2004. 1 DVD (115 min.), sonor., color.

FIORIN, J. L. Para entender o texto. São Paulo: Ática, 2001.

Semiótica e comunicação. In: DINIZ, L. V. P. \& PORTELA, J. C. (Org.). Semiótica e Mídia: textos, práticas, estratégias. Bauru: Unesp / FAAC, 2008, p. 75-92.

Sobre a tipologia dos discursos. Significação. Revista brasileira de Semiótica, São Paulo, n.8/9, p. 91-8, out. 1990.

FORSYTH, F. A alternativa do diabo. 2 ed. Tradução de A. B. Pinheiro de Lemos. Editora Record: Rio de Janeiro, 1979.

FLOCH, J.-M. Petites mythologies de l'oeil et de l'esprit. Paris: Hadès-Benjamins, 1985.

GREIMAS, A. J. \& COURTÉS, J. Dicionário de semiótica. Tradução Alceu Dias Lima et al. São Paulo: Cultrix, 1979.

GUERRA ao terror. Direção: Kathryn Bigelow. Estados Unidos: First Light Productions / Kingsgate Films / Grosvenor Park Media, 2009. 1 DVD (131 min.), sonor., color.

HOLLANDA, C. B. de. Fazenda modelo. 5 ed. Rio de Janeiro: Editora Civilização Brasileira, 1975.

HOMEM-ARANHA 2. Direção: Sam Raimi. Estados Unidos: Columbia Pictures Corporation, 2004. 1 DVD (127 min.), sonor., color.

KUNDERA, M. A insustentável leveza do ser. Tradução de Teresa B. Carvalho da Fonseca. Rio de Janeiro: Nova Fronteira, 1985a.

Risíveis amores. 10 ed. Tradução de Teresa B. Carvalho da Fonseca. Rio de Janeiro: Nova Fronteira, 1985b.

MERENCIANO, L. H. Autoajuda e esoterismo: uma sugestão tipológica. Revista do GEL, São Paulo, v. 6, n. 1, p. 151-177. 2009. Disponível em:

<http://www.gel.org.br/revistadogel/volumes/6/RG_V6N1_08.pdf $>$.

MORIN, E. Cultura de massas no século XX: o espírito do tempo. Rio de Janeiro: Forense, 1987.

PAIVA, C. C. O cinema de Hollywood e a Invenção da América. Biblioteca Online de

Ciências da Comunicação (BOCC). Portugal: Universidade da Beira Interior de Covilhã. 15 p. Disponível em: <http://www.bocc.uff.br/pag/paiva-claudio-hollywood-invencaoamerica.pdf>. Acesso em: 21 ago. 2010.

PEÑUELA CAÑIZAL, E. Tessituras oníricas em Morangos Silvestres. In: PEÑUELA CAÑIZAL, E. \& CAETANO, E. K. (Orgs.). Olhar à deriva: mídia, significação e cultura. São Paulo: Annablume, 2004. 
CASA, Vol.9 n.1, julho de 2011

PIETROFORTE, A. V. Semiótica visual: os percursos do olhar. São Paulo: Contexto, 2004. Análise do texto visual: a construção da imagem. São Paulo: Contexto, 2007.

ROCKY 4. Direção: Sylvester Stallone. Estados Unidos: MGM, 1985. 1 DVD (91 min.), sonor., color.

SHELDON, S. As areias do tempo. Tradução de A. B. Pinheiro de Lemos. São Paulo: Círculo do Livro, 1989.

SODRÉ, M. Best-seller: a literatura de mercado. 2. Ed. São Paulo: Ática, 1988.

VARGAS LLOSA, M. Conversa na catedral. Tradução de Olga Savary. São Paulo: Círculo do Livro, 1977.

WEST, M. O navegante. Tradução de A. B. Pinheiro de Lemos. 4. ed. Rio de Janeiro: Record, 1976.

X-MEN - o confronto final. Direção. Brett Ratner. Estados Unidos: 20th Century Fox Film Corporation, 2006. 1 DVD (103 min.), sonor., color.

YOURCENAR, M. Memórias de Adriano. Tradução de Martha Calderaro. 7 ed. Rio de Janeiro: Nova Fronteira, 1980.

ZONA verde. Direção: Paul Greengrass. Estados Unidos: Universal Pictures, 2010. 1 DVD (105 minutos), sonor., color. 